\title{
Efficacy and Safety of Tension-Free Vaginal Tape-Secur Mini- Sling Versus Standard Midurethral Slings for Female Stress Urinary Incontinence: A Systematic Review and Meta-Analysis
}

\author{
Wei Huang ${ }^{1,2}$, Tao Wang ${ }^{1,2}$, Huantao Zong ${ }^{1,2}$, Yong Zhang ${ }^{1,2}$ \\ ${ }^{1}$ Urology Department, Beijing Tian Tan Hospital, Capital Medical University, Beijing, China \\ ${ }^{2}$ Neurourology Research Division, China National Clinical Research Center for Neurological Disease, Beijing, China
}

Purpose: To assess the efficacy and safety of tension-free vaginal tape (TVT)-Secur for stress urinary incontinence (SUI). Methods: A literature review was performed to identify all published trials of TVT-Secur. The search included the following databases: MEDLINE, Embase, and the Cochrane Controlled Trial Register.

Results: Seventeen publications involving a total of 1,879 patients were used to compare TVT-Secur with tension-free obturator tape (TVT-O) and TVT. We found that TVT-Secur had significant reductions in operative time, visual analog score for pain, and postoperative complications compared with TVT-O. Even though TVT-Secur had a significantly lower subjective cure rate $(\mathrm{P}<0.00001)$, lower objective cure rate $(\mathrm{P}<0.00001)$, and higher intraoperative complication rate, compared with TVT-O at 1 to 3 years, there was no significant difference between TVT-Secur and TVT-O in the subjective cure rate (odds ratio [OR], $0.49 ; 95 \%$ confidence interval [CI], 0.22-1.08; $\mathrm{P}=0.08$ ), objective cure rate (OR, 0.49; 95\% CI, 0.22-1.09; $\mathrm{P}=0.08$ ), or complications at 3 to 5 years. Moreover, TVT-Secur had significantly lower subjective and objective cure rates compared with TVT.

Conclusions: This meta-analysis indicates that TVT-Secur did not show an inferior efficacy and safety compared with TVT$\mathrm{O}$ for SUI in 3 to 5 years, even though displaying a clear tread toward a lower efficacy in 1 to 3 years. Considering that the safety is similar, there are no advantages in using TVT-Secur.

Keywords: Urinary Incontinence, Stress; Suburethral Slings; Randomized Controlled Trial

- Fund Support: This study was supported by the Capital Characteristic Clinical Project of China.

- Conflict of Interest: No potential conflict of interest relevant to this article was reported.

\section{INTRODUCTION}

The International Continence Society defines stress urinary incontinence (SUI) as the complaint of involuntary urine leakage during effort, exertion, sneezing, or coughing [1]. It results from hypermobility of the urethra and functional insufficiency of the urethral sphincter. SUI affects $4 \%$ to $35 \%$ of women, and the prevalence increases with age [2]. Ten percent of middleaged women report daily or severe incontinence and at least one-third report leakage at least weekly [3].

SUI management is based on surgical options in case of failure of noninvasive therapies. Placement of a suburethral sling is the gold standard treatment for management of SUI associated with urethral hypermobility [4]. Tension-free vaginal tape
Corresponding author: Yong Zhang (iD http://orcid.org/0000-0001-9737-2553

Urology Department, Beijing Tian Tan Hospital, Capital Medical University, No. 6 Tiantan Xi Li, Dong cheng District, Beijing 100050, China

E-mail: doctorzhy@126.com / Tel: +86-10-6709-8393 / Fax: +86-10-6709-6611

-Wei Huang (iD http://orcid.org/0000-0002-1338-4213

Submitted: August 5, 2015 / Accepted after revision: September 7, 2015
This is an Open Access article distributed under the terms of the Creative Commons Attri(c) (1) \$ bution Non-Commercial License (http://creativecommons.org/licenses/ (c) ${ }_{\mathrm{BY}}$ Nc by-nc/3.0/) which permits unrestricted non-commercial use, distribution, and reproduction in any medium, provided the original work is properly cited. 
(TVT) and tension-free obturator tape (TVT-O) are widely used for this indication, with a high success rate and few complications [5]. Nevertheless, neither is completely free of complications, mainly due to the blind course of the introducer devices. The TVT course may perforate the bladder, whereas TVT-O passage is associated with vaginal perforation and neurologic impairment, leading to protracted thigh pain and upper leg weakness [6]. Both routes occasionally are associated with life-threatening complications, including bowel perforation, major vessel disruption, and perineal gangrene [7]. In addition, voiding dysfunction and vaginal mesh exposures may also complicate midurethral slings (MUS) [8].

Single-incision slings (SIS) were optimized to overcome these complications. TVT-Secur was the first single-incision device, and was developed in 2006. This device can be placed using a retropubic or " $U$ " approach, or a transobturator-like "hammock" approach [9]. The innovation was based on the use of shorter polypropylene laser-cut tape $(8 \mathrm{~cm} \times 1 \mathrm{~cm})$ through a single vaginal incision in order to avoid the retropubic space, obturator foramen, or groin muscles, and their related nerves and blood vessels.

Moreover, TVT-Secur seemed to cause less postoperative pain and reduced operative time [10], but its effectiveness seemed to be lower in comparison with traditional MUS $[11,12]$. However, a number of studies reported satisfactory results, including at midterm [13]. The anchoring mechanism of TVTSecur has been critically evaluated, with studies demonstrating a deterioration over time of the efficacy of this SIS, and calling for long-term studies of the surgical treatment of SUI [14]. Following these contrasting results, TVT-Secur was withdrawn from clinical practice by the manufacturer.

The goal of the present study was to perform a meta-analysis to evaluate the safety and efficacy of TVT-Secur compared with standard MUS in treating SUI, making the evidence available for the many women who had a TVT-Secur device implanted.

\section{MATERIALS AND METHODS}

\section{Search Strategy}

A systematic literature review was performed in August 2015. The MEDLINE, Embase, and Cochrane Controlled Trial Register databases were searched to identify relevant studies. Searches were restricted to publications in English. Two separate searches were done by applying a free-text protocol with the following search terms: stress urinary incontinence, suburethral slings, tension-free vaginal tape, and randomized controlled trials.

\section{Inclusion Criteria and Trial Selection}

Article selection proceeded according to the search strategy based on Preferred Reporting Items for Systematic Reviews and Meta-analysis criteria (Fig. 1). Only studies comparing TVTSecur and standard MUS were included for further screening. Cited references from the selected articles retrieved in the search were also assessed for significant papers. Conference abstracts were not included because they were not deemed to be methodologically appropriate. Two independent reviewers completed this process, and all disagreements were resolved through consensus.

\section{Quality Assessment}

The methodological quality of each study was assessed according to how patients were allocated to the arms of the study, the concealment of allocation procedures, blinding, and the data loss due to attrition. The studies were then classified qualitatively according to the guidelines published in the Cochrane Handbook for Systematic Reviews of Interventions 5.1.0 [15]. Based on the quality-assessment criteria, each study was rated and assigned to one of three quality categories: A, if all quality criteria were adequately met, the study was deemed to have a low risk of bias; $\mathrm{B}$, if one or more of the quality criteria was only partially met or was unclear, the study was deemed to have a moderate

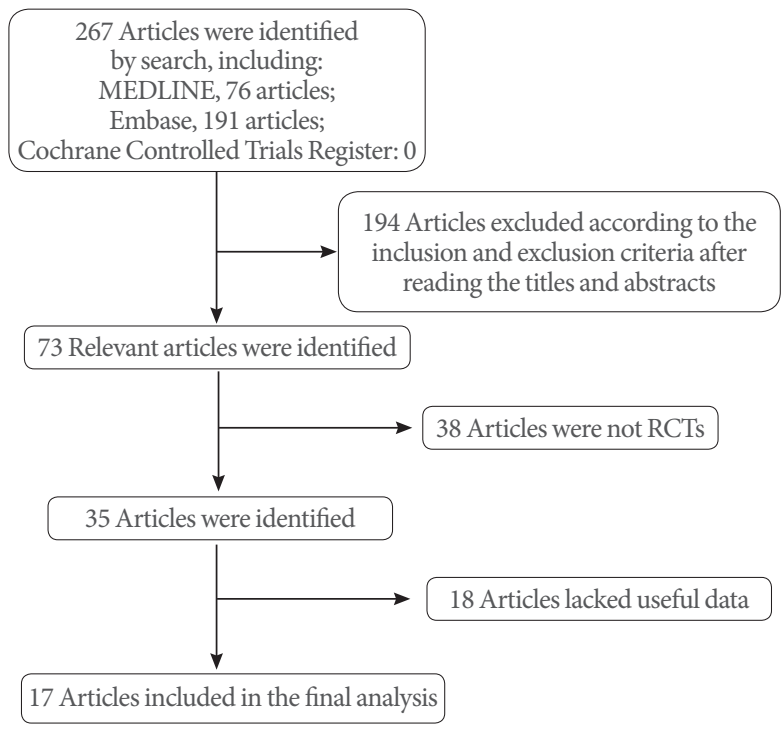

Fig. 1. The flow diagram of the study selection. RCT, randomized controlled trial. 
risk of bias; or C, if one or more of the criteria were not met, or not included, the study was deemed to have a high risk of bias. Sensitivity analyses were then performed on the basis of whether these quality factors were adequate, inadequate, or unclear. Differences were resolved by discussion among the reviewers.

\section{Data Extraction}

Data extracted from each eligible study included the name of the clinical trial, number of patients in each group, the therapy that the patients received, and the country in which the study was conducted. Data including operative time, subjective cure rate, objective cure rate, visual analog score (VAS) for pain, bleeding greater than $100 \mathrm{~mL}$, intraoperative complications, postoperative complications, reoperation for SUI, and de novo urgency were also extracted.

\section{Statistical Analysis}

The meta-analysis of comparable data was carried out with Review Manager 5.1.0 (The Cochrane Collaboration, London, UK). Due to the large number of plots, we combined 6 forest plots into 1 plot by using Adobe Photoshop CS (Adobe Systems, San Jose, CA, USA).

\section{RESULTS}

\section{Characteristics of Individual Studies}

The database search and reference lists of retrieved studies found 267 potential articles for our meta-analysis. Based on the inclusion and exclusion criteria, 194 articles were excluded after reading the titles and abstracts of the articles; 38 articles were not randomized controlled trials (RCTs), and 18 articles lacked useful data. In all, 17 articles [11,12,16-29] with 18 RCTs that compared TVT-Secur with standard MUS (TVT, TVT-O) were included in the analysis. The baseline characteristics of the studies included in our meta-analysis are listed in Table 1.

\section{Quality of Individual Studies}

All 18 RCTs were blinded, and all described the randomization processes that they had used. All included a power calculation to determine the optimal sample size (Table 2). The level of quality of each identified study was A to B (Table 2). The funnel plot provided a qualitative estimation of publication bias of the studies, and no evidence of bias was found (Fig. 2).

\section{TVT-Secur Compared With TVT-0 at 1 to 3 Years Efficacy}

Operative time (minute): Six RCTs represented 728 participants (360 in the TVT-Secur group and 368 in the TVT-O group) (Fig. 3). Based on our analysis, the pooled estimate of standardized mean difference (SMD) was -0.99 , and the $95 \%$ confidence interval $(\mathrm{CI})$ was -1.42 to $-0.57(\mathrm{P}<0.00001)$. This result suggests that TVT-Secur showed significant reductions in the mean operative time compared with TVT-O.

Subjective cure rate: Seven RCTs represented 791 participants (388 in the TVT-Secur group and 403 in the TVT-O group) (Fig. 4). According to our analysis, no heterogeneity was found among the trials, and a fixed-effects model was thus chosen for the analysis. Based on our analysis, the pooled estimate of odds ratio (OR) was 0.38 , and the $95 \%$ CI was 0.27 to 0.54 $(\mathrm{P}<0.00001)$. This result suggests that TVT-Secur showed a significantly lower subjective cure rate in comparison with TVT-O.

Objective cure rate: Eleven RCTs represented 1,076 participants (528 in the TVT-Secur group and 548 in the TVT-O group) (Fig. 4). According to our analysis, no heterogeneity was found among the trials, and a fixed-effects model was thus chosen for the analysis. Based on our analysis, the pooled estimate of OR was 0.26 , and the $95 \% \mathrm{CI}$ was 0.19 to $0.37(\mathrm{P}<0.00001)$. This result suggests that TVT-Secur showed a significantly lower objective cure rate in comparison with TVT-O.

\section{Safety}

VAS pain score (postoperative day 1): Three RCTs represented 265 participants (131 in the TVT-Secur group and 134 in the TVT-O group) (Fig. 3). According to our analysis, no heterogeneity was found among the trials, and a fixed-effects model was thus chosen for the analysis. Based on our analysis, the pooled estimate of SMD was -2.15 , and the $95 \%$ CI was -2.45 to -1.84 $(\mathrm{P}<0.00001)$. This result suggests that TVT-Secur showed significant reductions in the VAS score compared with TVT-O.

Bleeding greater than $100 \mathrm{~mL}$ : Six RCTs represented 791 participants (402 in the TVT-Secur group and 389 in the TVTO group) (Fig. 5). According to our analysis, no heterogeneity was found among the trials, and a fixed-effects model was thus chosen for the analysis. Based on our analysis, the pooled estimate of OR was 1.78 , and the $95 \%$ CI was 0.98 to 3.22 $(\mathrm{P}=0.06)$. This result suggests that TVT-Secur showed no significant difference in the rate of bleeding greater than $100 \mathrm{~mL}$ compared with TVT-O. 


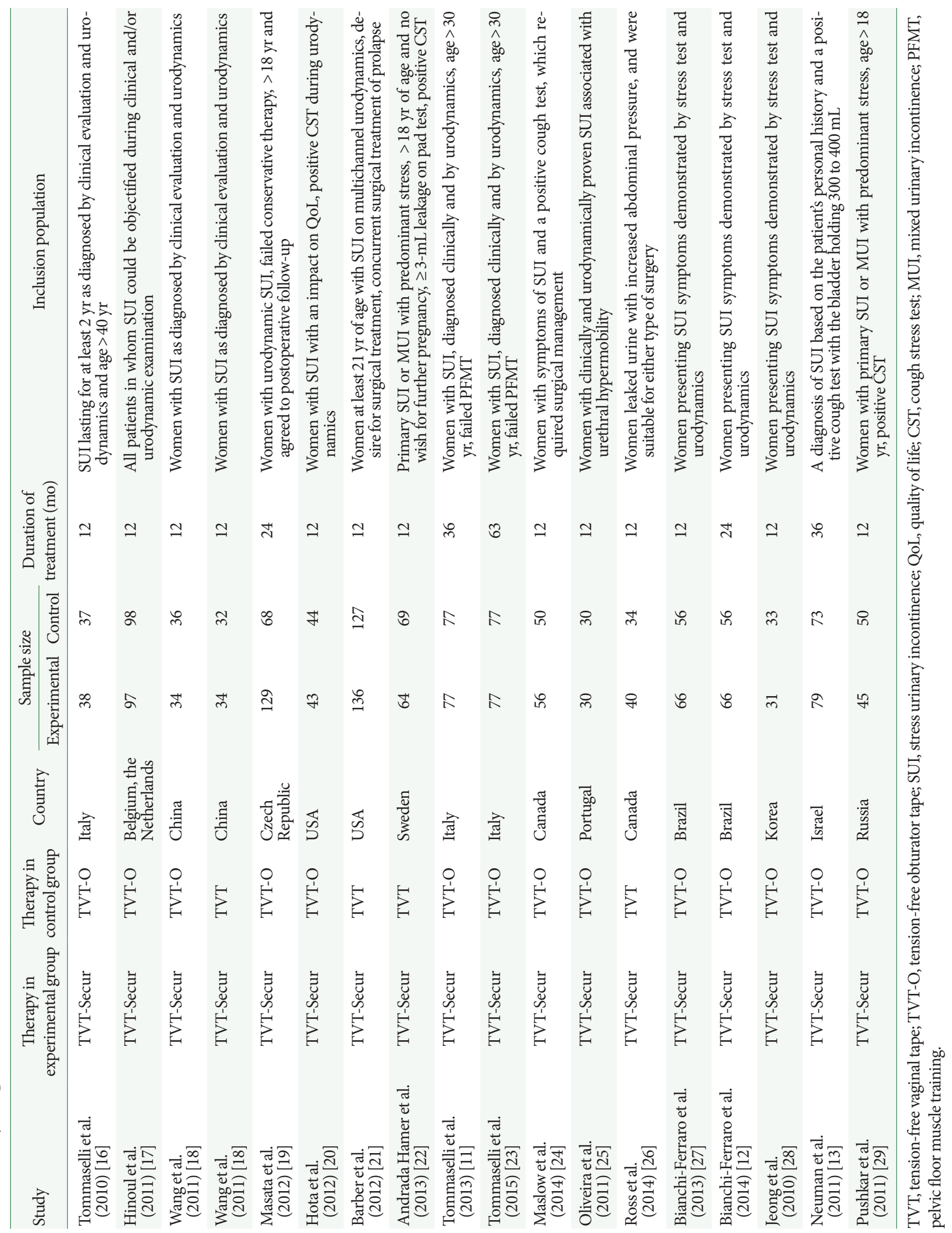




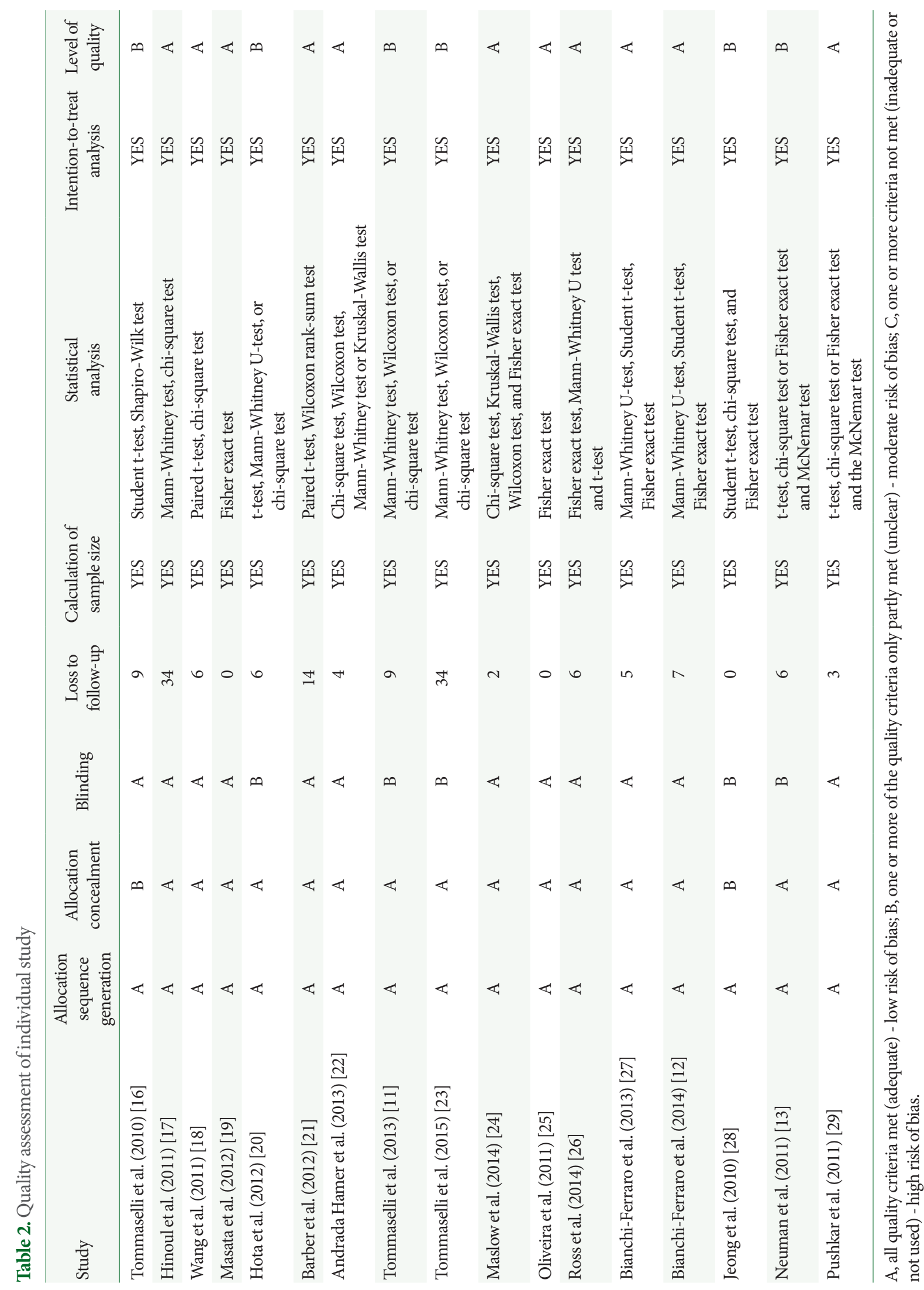


Intraoperative complications: Five RCTs represented 645 participants (325 in the TVT-Secur group and 320 in the TVT-O group) (Fig. 6). According to our analysis, no heterogeneity was found among the trials, and a fixed-effects model was thus chosen for the analysis. Based on our analysis, the pooled estimate of OR was 1.98 , and the $95 \%$ CI was 1.15 to $3.42(\mathrm{P}=0.01)$. This result suggests that TVT-Secur showed significant increases in the rate of intraoperative complications compared with TVT-O.

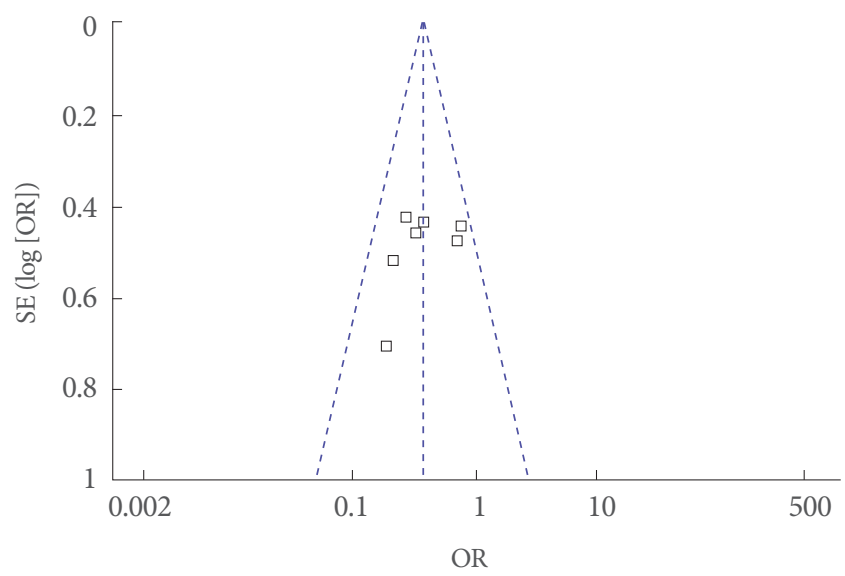

Fig. 2. Funnel plot of the studies represented in our meta-analysis. SE, standard error; OR, odds ratio.
Postoperative complications: Seven RCTs represented 780 participants (392 in the TVT-Secur group and 388 in the TVTO group) (Fig. 6). According to our analysis, no heterogeneity was found among the trials, and a fixed-effects model was thus chosen for the analysis. Based on our analysis, the pooled estimate of OR was 0.67 , and the $95 \%$ CI was 0.48 to 0.95 $(\mathrm{P}=0.03)$. This result suggests that TVT-Secur showed a significant decrease in the rate of postoperative complications compared with TVT-O.

De novo urgency: Eight RCTs represented 874 participants (439 in the TVT-Secur group and 435 in the TVT-O group) (Fig. 5). According to our analysis, no heterogeneity was found among the trials, and a fixed-effects model was thus chosen for the analysis. Based on our analysis, the pooled estimate of OR was 0.78 , and the $95 \% \mathrm{CI}$ was 0.50 to $1.91(\mathrm{P}=0.25)$. This result suggests that TVT-Secur showed no significant difference in the rate of de novo urgency compared with TVT-O.

Reoperation for SUI: Four RCTs represented 471 participants (229 in the TVT-Secur group and 242 in the TVT-O group) (Fig. 5). According to our analysis, no heterogeneity was found among the trials, and a fixed-effects model was thus chosen for the analysis. Based on our analysis, the pooled estimate of OR was 4.96 , and the $95 \%$ CI was 2.37 to $10.35(\mathrm{P}<0.0001)$. This

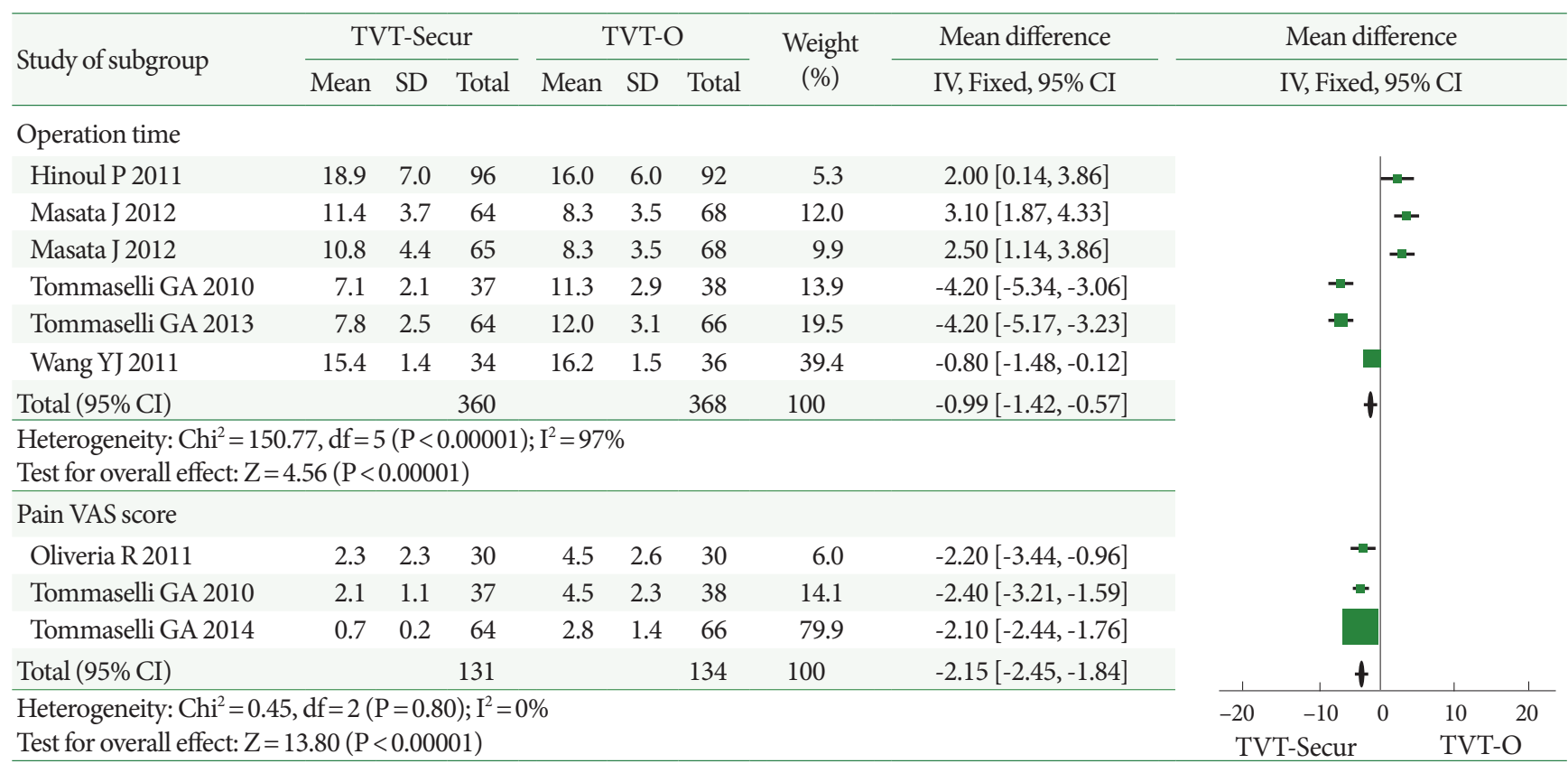

Fig. 3. Operative time, visual analog score (VAS) score (postoperative day 1) (TVT-Secur vs. TVT-O). TVT, tension-free vaginal tape; TVT-O, tension-free obturator tape; SD, standard deviation; IV, inverse variance; Fixed, fixed effect model; CI, confidence interval; df, degrees of freedom. 


\begin{tabular}{|c|c|c|c|c|c|c|c|c|}
\hline \multirow{2}{*}{ Study of subgroup } & \multicolumn{2}{|c|}{ TVT-Secur } & \multicolumn{2}{|c|}{ TVT-O } & \multirow{2}{*}{$\begin{array}{l}\text { Weight } \\
(\%)\end{array}$} & \multirow{2}{*}{$\begin{array}{c}\text { Odds ratio } \\
\text { M-H, Fixed, } 95 \% \text { CI }\end{array}$} & \multirow{2}{*}{\multicolumn{2}{|c|}{$\begin{array}{c}\text { Odds ratio } \\
\text { M-H, Fixed, } 95 \% \text { CI }\end{array}$}} \\
\hline & Events & Total & Events & Total & & & & \\
\hline \multicolumn{9}{|l|}{ Subjective cure in $1-3$ years } \\
\hline Bianchi-Ferraro AM 2014 & 50 & 66 & 45 & 56 & 11.1 & $0.76[0.32,1.82]$ & & \\
\hline Hinoul P 2011 & 57 & 75 & 77 & 85 & 16.2 & $0.33[0.13,0.81]$ & & \\
\hline Masata J 2012 & 40 & 65 & 58 & 68 & 20.4 & $0.28[0.12,0.64]$ & & \\
\hline Masata J 2012 & 44 & 64 & 58 & 68 & 16.5 & $0.38[0.16,0.89]$ & & \\
\hline Maslow K 2014 & 32 & 52 & 44 & 50 & 16.2 & $0.22[0.08,0.60]$ & & \\
\hline Pushkar DI 2011 & 14 & 32 & 21 & 40 & 9.8 & $0.70[0.28,1.79]$ & & \\
\hline Wang YJ 2011 & 23 & 34 & 33 & 36 & 9.7 & $0.19[0.05,0.76]$ & & \\
\hline Total $(95 \%$ CI $)$ & & 388 & & 403 & 100 & $0.38[0.27,0.54]$ & & \\
\hline Total events & 260 & & 336 & & & & & \\
\hline \multicolumn{7}{|c|}{$\begin{array}{l}\text { Heterogeneity, } \mathrm{Chi}^{2}=6.93, \mathrm{df}=6(\mathrm{P}=0.33) ; \mathrm{I}^{2}=13 \% \\
\text { Test for overall effect: } \mathrm{Z}=5.45(\mathrm{P}<0.00001)\end{array}$} & & \\
\hline \multicolumn{9}{|c|}{ Objective cure in $1-3$ years } \\
\hline Bianchi-Ferraro AM 2014 & 51 & 66 & 48 & 56 & 8.2 & $0.57[0.22,1.46]$ & & \\
\hline Hinoul P 2011 & 62 & 75 & 82 & 85 & 9.3 & $0.17[0.05,0.64]$ & & \\
\hline Hota LS 2012 & 20 & 42 & 40 & 44 & 14.2 & $0.09[0.03,0.30]$ & & \\
\hline Jeong MY 2010 & 22 & 31 & 28 & 33 & 5.5 & $0.44[0.13,1.49]$ & & \\
\hline Masata J 2012 & 45 & 65 & 63 & 68 & 13.2 & $0.18[0.06,0.51]$ & & \\
\hline Masata J 2012 & 44 & 64 & 63 & 68 & 13.3 & $0.17[0.06,0.50]$ & & \\
\hline Maslow K 2014 & 33 & 52 & 43 & 50 & 11.1 & $0.28[0.11,0.75]$ & & \\
\hline Oliveria R 2011 & 20 & 30 & 25 & 30 & 5.8 & $0.40[0.12,1.36]$ & & \\
\hline Pushkar DI 2011 & 20 & 32 & 38 & 40 & 8.8 & $0.09[0.02,0.43]$ & & \\
\hline Tommaselli GA 2010 & 31 & 37 & 31 & 38 & 3.4 & $1.17[0.35,3.87]$ & & \\
\hline Wang YJ 2011 & 23 & 34 & 33 & 36 & 7.2 & $0.19[0.05,0.76]$ & & \\
\hline Total $(95 \%$ CI $)$ & & 528 & & 548 & 100 & $0.26[0.19,0.37]$ & & \\
\hline Total events & 371 & & 494 & & & & & \\
\hline \multicolumn{7}{|c|}{$\begin{array}{l}\text { Heterogeneity: } \mathrm{Chi}^{2}=16.17, \mathrm{df}=10(\mathrm{P}=0.09) ; \mathrm{I}^{2}=38 \% \\
\text { Test for overall effect: } \mathrm{Z}=7.79(\mathrm{P}<0.00001)\end{array}$} & & \\
\hline \multicolumn{9}{|c|}{ Subjective cure in $3-5$ years } \\
\hline Neuman M 2011 & 70 & 77 & 60 & 60 & 35.5 & $0.08[0.00,1.39]$ & & \\
\hline Tommaselli GA 2013 & 50 & 64 & 55 & 66 & 64.5 & $0.71[0.30,1.72]$ & & \\
\hline Total $(95 \%$ CI $)$ & & 141 & & 126 & 100 & $0.49[0.22,1.08]$ & & \\
\hline Total events & 120 & & 115 & & & & & \\
\hline \multicolumn{7}{|c|}{$\begin{array}{l}\text { Heterogeneity: } \mathrm{Chi}^{2}=2.28, \mathrm{df}=1(\mathrm{P}=0.13) ; \mathrm{I}^{2}=56 \% \\
\text { Test for overall effect: } \mathrm{Z}=1.77(\mathrm{P}=0.08)\end{array}$} & & \\
\hline \multicolumn{9}{|c|}{ Objective cure in $3-5$ years } \\
\hline Neuman M 2011 & 70 & 77 & 58 & 60 & 32.6 & $0.34[0.07,1.72]$ & & \\
\hline Tommaselli GA 2013 & 50 & 64 & 57 & 66 & 67.4 & $0.56[0.22,1.41]$ & & \\
\hline Total (95\% CI) & & 141 & & 126 & 100 & $0.49[0.22,1.09]$ & & \\
\hline Total events & 120 & & 115 & & & & & \\
\hline \multicolumn{7}{|c|}{$\begin{array}{l}\text { Heterogeneity: } \mathrm{Chi}^{2}=0.27, \mathrm{df}=1(\mathrm{P}=0.60) ; \mathrm{I}^{2}=0 \% \\
\text { Test for overall effect: } \mathrm{Z}=1.75(\mathrm{P}=0.08)\end{array}$} & $\begin{array}{l}0.001 \quad 0.1 \\
\text { TVT-Secur }\end{array}$ & $\begin{array}{l}10 \quad 1,000 \\
\text { TVT-O }\end{array}$ \\
\hline
\end{tabular}

Fig. 4. Subjective and objective cure rate at 1-3 years and 3-5 years (TVT-Secur vs. TVT-O). TVT, tension-free vaginal tape; TVT-O, tension-free obturator tape; M-H, Mantel-Haenszel method; Fixed, fixed effect model; CI, confidence interval; df, degrees of freedom.

result suggests that TVT-Secur showed a significant increase in the rate of reoperation for SUI compared with TVT-O.
TVT-Secur Compared With TVT-O at 3 to 5 Years Subjective cure rate

Two RCTs represented 267 participants (141 in the TVT-Secur 


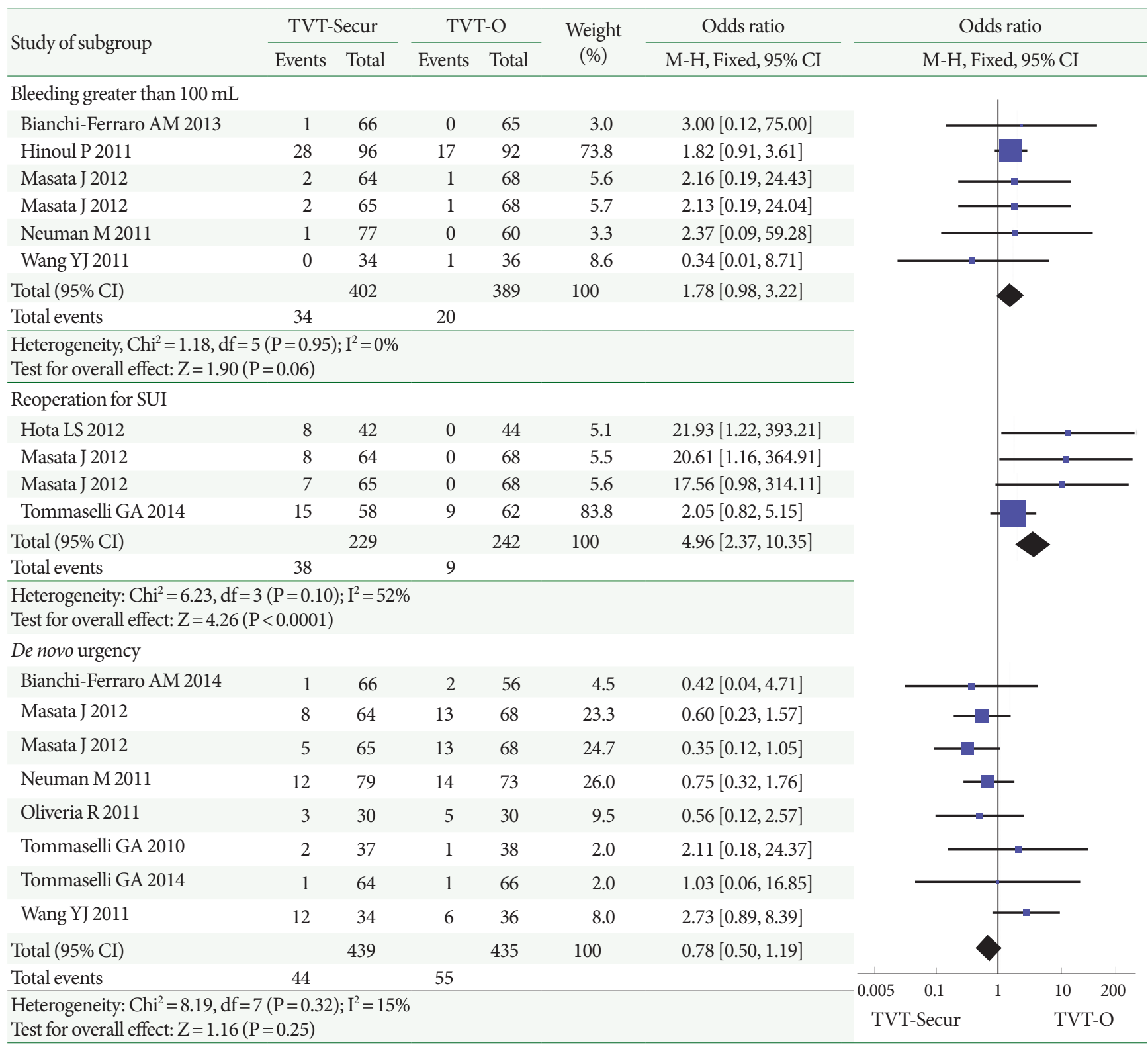

Fig. 5. Bleeding greater than $100 \mathrm{~mL}$, reoperation for stress urinary incontinence (SUI), and de novo urgency (TVT-Secur vs. TVTO). TVT, tension-free vaginal tape; TVT-O, tension-free obturator tape; M-H, Mantel-Haenszel method; Fixed, fixed effect model; $\mathrm{CI}$, confidence interval; df, degrees of freedom.

group and 126 in the TVT-O group) (Fig. 4). According to our analysis, no heterogeneity was found among the trials, and a fixed-effects model was thus chosen for the analysis. Based on our analysis, the pooled estimate of OR was 0.49 , and the $95 \%$ CI was 0.22 to $1.08(\mathrm{P}=0.08)$. This result suggests that TVT-Secur showed no significant difference in subjective cure rate in comparison with TVT-O.

\section{Objective cure rate}

Two RCTs represented 267 participants (141 in the TVT-Secur group and 126 in the TVT-O group) (Fig. 4). According to our analysis, no heterogeneity was found among the trials, and a fixed-effects model was thus chosen for the analysis. Based on our analysis, the pooled estimate of OR was 0.49 , and the $95 \%$ CI was 0.22 to $1.09(\mathrm{P}=0.08)$. This result suggests that TVT-Secur showed no significant difference in objective cure rate in 


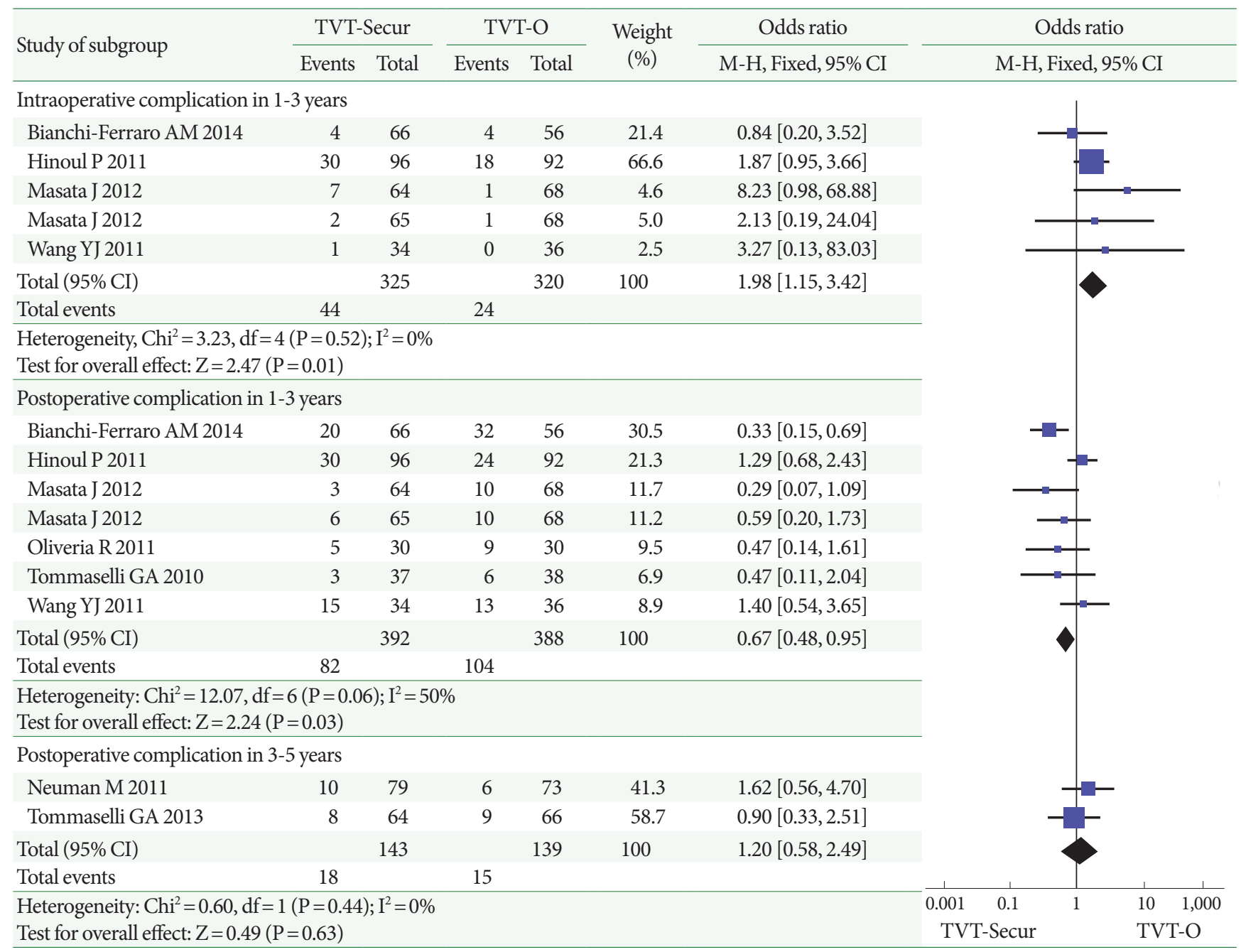

Fig. 6. Complications: intraoperative or postoperative complications at 1-3 years, postoperative complications at 3-5 years (TVT-Secur vs. TVT-O). TVT, tension-free vaginal tape; TVT-O, tension-free obturator tape; M-H, Mantel-Haenszel method; Fixed, fixed effect model; CI, confidence interval; df, degrees of freedom.

comparison with TVT-O.

\section{Postoperative complications}

Two RCTs represented 282 participants (143 in the TVT-Secur group and 139 in the TVT-O group) (Fig. 6). According to our analysis, no heterogeneity was found among the trials, and a fixed-effects model was thus chosen for the analysis. Based on our analysis, the pooled estimate of OR was 1.20 , and the $95 \%$ CI was 0.58 to $2.49(\mathrm{P}=0.63)$. This result suggests that TVT-Secur showed no significant difference in the rate of postoperative complications compared with TVT-O.

\section{TVT-Secur Compared With TVT Efficacy}

Subjective cure rate: Three RCTs represented 444 participants (226 in the TVT-Secur group and 218 in the TVT group) (Fig. 7). According to our analysis, no heterogeneity was found among the trials, and a fixed-effects model was thus chosen for the analysis. Based on our analysis, the pooled estimate of OR was 0.59 , and the $95 \% \mathrm{CI}$ was 0.39 to $0.88(\mathrm{P}=0.01)$. This result suggests that TVT-Secur showed a significantly lower subjective cure rate in comparison with TVT.

Objective cure rate: Three RCTs represented 248 participants (127 in the TVT-Secur group and 121 in the TVT group) (Fig. 7). According to our analysis, no heterogeneity was found 


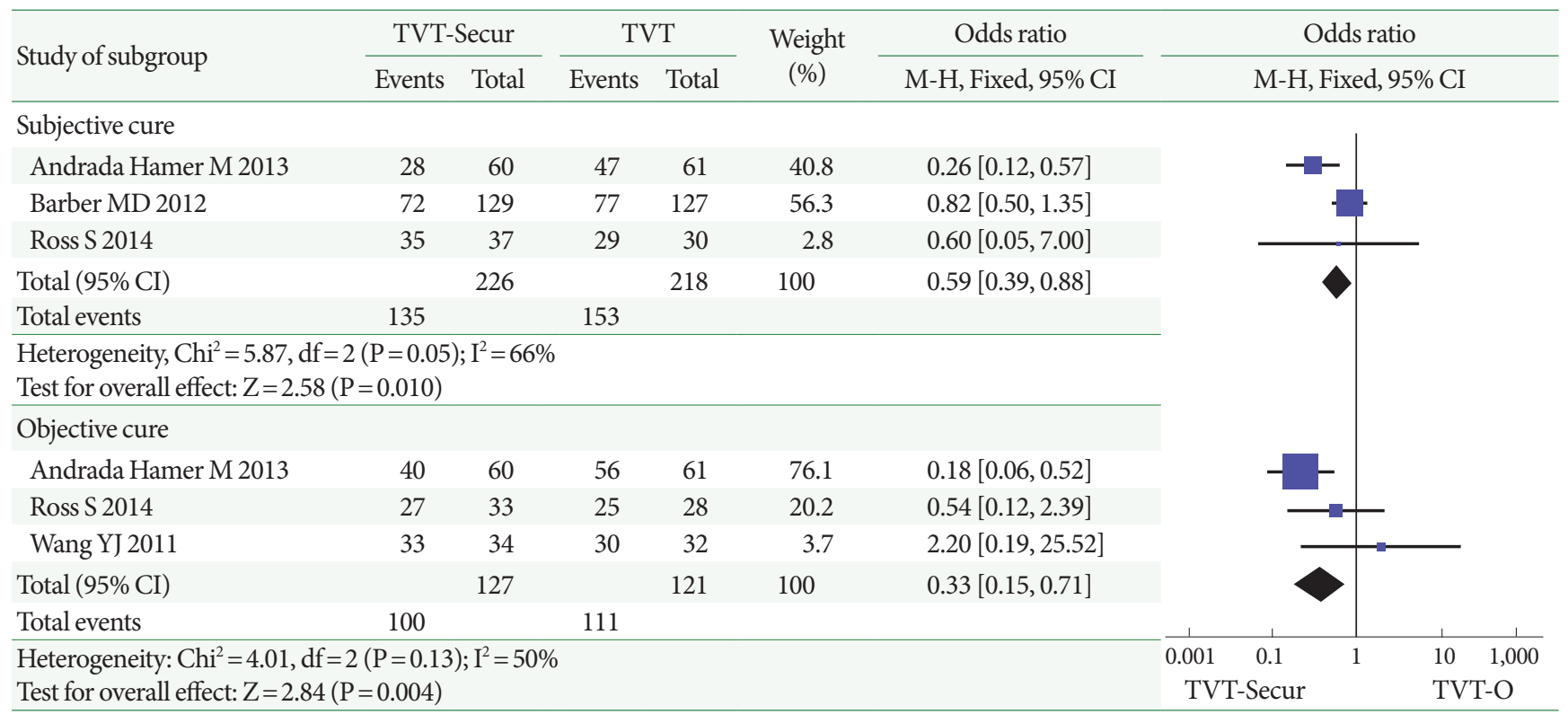

Fig. 7. Subjective and objective cure rate (TVT-Secur vs. TVT). TVT, tension-free vaginal tape; M-H, Mantel-Haenszel method; Fixed, fixed effect model; CI, confidence interval; df, degrees of freedom.

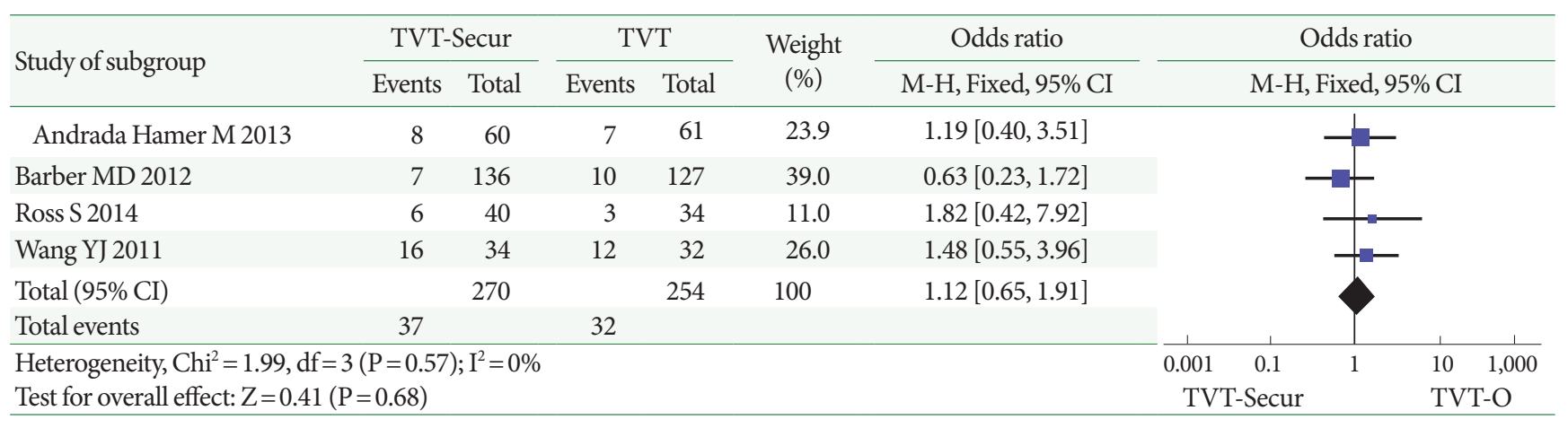

Fig. 8. Complications (TVT-Secur vs. TVT). TVT, tension-free vaginal tape; M-H, Mantel-Haenszel method; Fixed, fixed effect model; CI, confidence interval; df, degrees of freedom.

among the trials, and a fixed-effects model was thus chosen for the analysis. Based on our analysis, the pooled estimate of OR was 0.33 , and the $95 \%$ CI was 0.15 to $0.71(\mathrm{P}=0.004)$. This result suggests that TVT-Secur showed a significantly lower objective cure rate in comparison with TVT.

\section{Safety}

Complications: Four RCTs represented 524 participants (270 in the TVT-Secur group and 254 in the TVT group) (Fig. 8). According to our analysis, no heterogeneity was found among the trials, and a fixed-effects model was thus chosen for the analysis. Based on our analysis, the pooled estimate of OR was 1.12, and the $95 \% \mathrm{CI}$ was 0.65 to $1.91(\mathrm{P}=0.68)$. This result suggests that TVT-Secur showed no significant difference in the rate of complications compared with TVT.

\section{DISCUSSION}

As a third-generation device, TVT-Secur was first used in 2006. The new so-called minimally invasive devices have been developed to limit groin pain after sling placement while aiming at comparable success results. TVT-Secur minimizes operative dissection and risk of injury of periurethral elements and pelvic organs, as well as the risk of nerve or adductor muscle damage. 
However, TVT-Secur was withdrawn from clinical practice by the manufacturer due to poor efficacy.

Our study reveals that there was no evidence of significant differences between TVT-Secur and TVT-O for bleeding greater than $100 \mathrm{~mL}$ or de novo urgency. There were also no significant differences between TVT-Secur and TVT in complication rates. However, our study found that TVT-Secur has a higher reoperation rate for SUI and intraoperative complication rate compared with TVT-O. Some reports highlighted the risk of severe bleeding following TVT-Secur positioning [30,31]. Larsson et al. [31] recently reported an injury of the corona mortis, an anomaly of the vessels combining the obturator and epigastric arteries passing over the superior pubic ramus. Both cases required surgical intervention to remove clots, identify the site of bleeding, and perform hemostasis. Another report [16] thought that the severe blood loss (approximately $400 \mathrm{~mL}$ ) experienced by one patient undergoing TVT-Secur was probably from the internal obturator muscle, and was treated conservatively by immediate compression of the muscle with vaginal packing. These data suggest that severe bleeding for TVT-Secur positioning is possible. In the TVT-Secur group, the main postoperative complication was de novo urgency, which may be related to tension difficulties with this kind of device. Higher de novo urgency rates $(5 \%-35 \%)$ have been published [18,21], but were not significantly different from the rate observed in the TVT-O group.

Thigh pain is one of the most frequent complications of TVT-O, and TVT-Secur was associated with less postoperative pain [17]. Although we observed a statistical difference in postoperative pain, both groups presented average pain scores $<3$, which are considered mild according to the VAS [32]. TVT-Secur was associated with less thigh pain than TVT-O, possibly due to absence of involvement of the nerve or adductor muscles. However, all women were free from this symptom within a month following surgery. Moreover, operative time was significantly reduced in the TVT-Secur group.

Our meta-analysis indicated that TVT-Secur had significantly worse subjective and objective outcomes than standard MUS at 1 to 3 years. However, at 3 to 5 years, we found that there was no significant difference in subjective or objective cure rates in comparison with TVT-O. The subjective and objective cure rate of TVT-Secur is $69.7 \%$ and $70 \%$ at 1 to 3 years, and $59.7 \%$ and $78 \%$ at 3 to 5 years, respectively. Tommaselli et al. [23] recently reported that subjective success $(63.8 \%)$ and objective cure rates $(68.4 \%)$ over 5 years were lower for TVTSecur than TVT-O, but not significantly. The reason may be that many patients with TVT-Secur who failed at 1 to 3 years may have had other operations, which were not included at 3 to 5 years of follow-up. Moreover, in comparison with the 36-month follow-up, TVT-Secur showed a greater decrease in subjective cure rate than TVT-O [23]. These data seem to indicate that the subjective cure rate of TVT-Secur decreases over time more than that of TVT-O, although not significantly. Indeed, a limitation of our study is the sample size of patients. With a larger sample size, the study may demonstrate a difference in outcomes between TVT-Secur and TVT-O at 3 to 5 years. As for objective cure rate, this discrepancy may be explained by the fact that objective evaluation may not reflect normal daily activities, and thus underestimates the incidence of recurrent SUI. The fact that TVT-Secur has been associated with lower cure rates deserves some consideration. The failure at 1-3 years is mainly linked to an incorrect positioning or early failure of the sling, and recurrences are probably due to insufficiency of the tape in avoiding SUI. As for the many women who had a TVT-Secur device implanted, reoperation is a problem. The clinical relevance of the decline of the efficacy of TVTSecur, and the limited advantages of this device in the longterm, in particular, suggest that TVT-O may be a better choice, when all factors are considered.

In summary, TVT-Secur failed to demonstrate high clinical efficacy for SUI. Indeed, only $70.8 \%$ of patients treated with TVT-Secur remained cured, whereas $90.7 \%$ of patients treated with TVT-O remained cured after a median follow-up of 32 months. These results are influenced by previous incontinence surgery and a cystocele grade $\geq 2$ [33]. Multivariate analysis also showed that only low Valsalva leak point pressure $<60 \mathrm{~cm} \mathrm{H}_{2} \mathrm{O}$ was associated with a lower cure rate [34]. Therefore, these factors should be carefully evaluated when choosing a TVT-Secur procedure, to provide sufficient information to patients. TVTO or TVT are still the first-line treatments for female SUI.

This meta-analysis includes studies in which all findings are from randomized double-blind, placebo-controlled trials. According to the quality-assessment scale that we developed, the quality of the individual studies in the meta-analysis was conforming. The results of this analysis acquire great importance from a scientific standpoint, but also for daily clinical practice. However, the number of included studies was not large. Longerterm safety, efficacy, and stability of TVT-Secur cannot be extrapolated from this article, as the sample size is limited. In addition, unpublished data were not included in the analysis. Besides, there is a discrepancy in the number of parameters used 
in comparing the procedures. Nine parameters were evaluated for the analysis of TVT-Secur compared with TVT-O at 1 to 3 years. As the data were limited, a carefully structured analysis comparing TVT-S with TVT-O at 3 to 5 years could not be done, and only 3 parameters were evaluated. This may compromise the value of the study results, and these factors may have resulted in bias. More high-quality trials with larger samples are proposed to learn more about the efficacy and safety of the therapy for female SUI.

In conclusion, this meta-analysis indicates that TVT-Secur did not show an inferior efficacy and safety compared with TVT-O for SUI in 3 to 5 years, even though displaying a clear tread toward a lower efficacy in 1 to 3 years. Considering that the safety is similar, there are no advantages in using TVT-Secur.

\section{REFERENCES}

1. Abrams P, Blaivas JG, Stanton SL, Andersen JT. The standardisation of terminology of lower urinary tract function. The International Continence Society Committee on Standardisation of Terminology. Scand J Urol Nephrol Suppl 1988;114:5-19.

2. Luber KM. The definition, prevalence, and risk factors for stress urinary incontinence. Rev Urol 2004;6 Suppl 3:S3-9.

3. de Leval J. Novel surgical technique for the treatment of female stress urinary incontinence: transobturator vaginal tape inside-out. Eur Urol 2003;44:724-30.

4. Wilson TS, Lemack GE. Transvaginal surgery for stress incontinence. In: Carlin B, Leong F, editors. Female pelvic health and reproductive surgery. New York: Marcel Dekker Inc:; 2003. p. 137-50.

5. Hsiao SM, Chang TC, Lin HH. Risk factors affecting cure after mid-urethral tape procedure for female urodynamic stress incontinence: comparison of retropubic and transobturator routes. Urology 2009;73:981-6.

6. Daneshgari F, Kong W, Swartz M. Complications of mid urethral slings: important outcomes for future clinical trials. J Urol 2008;180: 1890-7.

7. Deng DY, Rutman M, Raz S, Rodriguez LV. Presentation and management of major complications of midurethral slings: are complications under-reported? Neurourol Urodyn 2007;26:46-52.

8. Novara G, Galfano A, Boscolo-Berto R, Secco S, Cavalleri S, Ficar$\mathrm{ra} \mathrm{V}$, et al. Complication rates of tension-free midurethral slings in the treatment of female stress urinary incontinence: a systematic review and meta-analysis of randomized controlled trials comparing tension-free midurethral tapes to other surgical procedures and different devices. Eur Urol 2008;53:288-308.
9. Hubka P, Masata J, Nanka O, Grim M, Martan A, Zvarova J. Anatomical relationship and fixation of tension-free vaginal tape Secur. Int Urogynecol J Pelvic Floor Dysfunct 2009;20:681-8.

10. Mostafa A, Lim CP, Hopper L, Madhuvrata P, Abdel-Fattah M. Single-incision mini-slings versus standard midurethral slings in surgical management of female stress urinary incontinence: an updated systematic review and meta-analysis of effectiveness and complications. Eur Urol 2014;65:402-27.

11. Tommaselli GA, D’Afiero A, Di Carlo C, Formisano C, Fabozzi A, Nappi C. Tension-free vaginal tape-O and -Secur for the treatment of stress urinary incontinence: a thirty-six-month follow-up singleblind, double-arm, randomized study. J Minim Invasive Gynecol 2013;20:198-204.

12. Bianchi-Ferraro AM, Jarmy-DiBella ZI, de Aquino Castro R, Bortolini MA, Sartori MG, Girao MJ. Randomized controlled trial comparing TVT-O and TVT-S for the treatment of stress urinary incontinence: 2-year results. Int Urogynecol J 2014;25:1343-8.

13. Neuman M, Sosnovski V, Kais M, Ophir E, Bornstein J. Transobturator vs single-incision suburethral mini-slings for treatment of female stress urinary incontinence: early postoperative pain and 3-year follow-up. J Minim Invasive Gynecol 2011;18:769-73.

14. Hilton P. Long-term follow-up studies in pelvic floor dysfunction: the Holy Grail or a realistic aim? BJOG 2008;115:135-43.

15. Higgins JP, Green S, editors. Cochrane handbook for systematic reviews of interventions. version 5.1.0 [Internet]. The Cochrane Collaboration, 2011 [uptated 2011 Mar; cited 2015 Apr 1]. Available from: www.cochrane-handbook.org.

16. Tommaselli GA, Di Carlo C, Gargano V, Formisano C, Scala M, Nappi C. Efficacy and safety of TVT-O and TVT-Secur in the treatment of female stress urinary incontinence: 1-year follow-up. Int Urogynecol J 2010;21:1211-7.

17. Hinoul P, Vervest HA, den Boon J, Venema PL, Lakeman MM, Milani AL, et al. A randomized, controlled trial comparing an innovative single incision sling with an established transobturator sling to treat female stress urinary incontinence. J Urol 2011;185:1356-62.

18. Wang YJ, Li FP, Wang Q, Yang S, Cai XG, Chen YH. Comparison of three mid-urethral tension-free tapes (TVT, TVT-O, and TVTSecur) in the treatment of female stress urinary incontinence: 1-year follow-up. Int Urogynecol J 2011;22:1369-74.

19. Masata J, Svabik K, Zvara K, Drahoradova P, El Haddad R, Hubka P, et al. Randomized trial of a comparison of the efficacy of TVT-O and single-incision tape TVT SECUR systems in the treatment of stress urinary incontinent women--2-year follow-up. Int Urogynecol J 2012;23:1403-12.

20. Hota LS, Hanaway K, Hacker MR, Disciullo A, Elkadry E, Drami- 
tinos P, et al. TVT-Secur (Hammock) versus TVT-Obturator: a randomized trial of suburethral sling operative procedures. Female Pelvic Med Reconstr Surg 2012;18:41-5.

21. Barber MD, Weidner AC, Sokol AI, Amundsen CL, Jelovsek JE, Karram MM, et al. Single-incision mini-sling compared with tension-free vaginal tape for the treatment of stress urinary incontinence: a randomized controlled trial. Obstet Gynecol 2012;119(2 Pt 1):328-37.

22. Andrada Hamer M, Larsson PG, Teleman P, Bergqvist CE, Persson J. One-year results of a prospective randomized, evaluator-blinded, multicenter study comparing TVT and TVT Secur. Int Urogynecol J 2013;24:223-9.

23. Tommaselli GA, D’Afiero A, Di Carlo C, Formisano C, Fabozzi A, Nappi $\mathrm{C}$. Tension-free vaginal tape-obturator and tension-free vaginal tape-Secur for the treatment of stress urinary incontinence: a 5-year follow-up randomized study. Eur J Obstet Gynecol Reprod Biol 2015;185:151-5.

24. Maslow K, Gupta C, Klippenstein P, Girouard L. Randomized clinical trial comparing TVT Secur system and trans vaginal obturator tape for the surgical management of stress urinary incontinence. Int Urogynecol J 2014;25:909-14.

25. Oliveira R, Botelho F, Silva P, Resende A, Silva C, Dinis P, et al. Exploratory study assessing efficacy and complications of TVT-O, TVT-Secur, and Mini-Arc: results at 12-month follow-up. Eur Urol 2011;59:940-4.

26. Ross S, Tang S, Schulz J, Murphy M, Goncalves J, Kaye S, et al. Single incision device (TVT Secur) versus retropubic tension-free vaginal tape device (TVT) for the management of stress urinary incontinence in women: a randomized clinical trial. BMC Res
Notes 2014;7:941.

27. Bianchi-Ferraro AM, Jarmy-Di Bella ZI, Castro Rde A, Bortolini MA, Sartori MG, Girão MJ. Single-incision sling compared with transobturator sling for treating stress urinary incontinence: a randomized controlled trial. Int Urogynecol J 2013;24:1459-65.

28. Jeong MY, Kim SJ, Kim HS, Koh JS, Kim JC. Comparison of efficacy and satisfaction between the TVT-SECUR and MONARC procedures for the treatment of female stress urinary incontinence. Korean J Urol 2010;51:767-71.

29. Pushkar' DIu, Kasian GR, Gvozdev MIu, Lynova IuL, Kupriianov IuA. Mini-invasive operations for correction of urinary incontinence in females. Urologiia 2011;(4):16-20.

30. Masata J, Martan A, Svabik K. Severe bleeding from internal obturator muscle following tension-free vaginal tape Secur hammock approach procedure. Int Urogynecol J Pelvic Floor Dysfunct 2008; 19:1581-3.

31. Larsson PG, Teleman P, Persson J. A serious bleeding complication with injury of the corona mortis with the TVT-Secur procedure. Int Urogynecol J 2010;21:1175-7.

32. Collins SL, Moore RA, McQuay HJ. The visual analogue pain intensity scale: what is moderate pain in millimetres? Pain 1997;72:95-7.

33. Hwang E, Shin JH, Lim JS, Song KH, Sul CK, Na YG. Predictive factors that influence treatment outcomes of innovative single incision sling: comparing TVT-Secur to an established transobturator sling for female stress urinary incontinence. Int Urogynecol J 2012; 23:907-12.

34. Han JY, Park J, Choo MS. Efficacy of TVT-SECUR and factors affecting cure of female stress urinary incontinence: 3-year followup. Int Urogynecol J 2012;23:1721-6. 